\title{
UTILIZATION OF BANANA PEEL AS A BIOSORBENT FOR THE REMOVAL OF BASIC RED 29 FROM AQUEOUS SOLUTION
}

\author{
JEN-KAI CHONGa, SIEW-TENG ONGa,b,
}

\begin{abstract}
The banana peel powder (BPP) was used as a low-cost adsorbent for the adsorption of Basic Red 29 (BR29) dye from aqueous solution. The FTIR, AFM and SEM analysis were conducted for the characterization of BPP. The effects of initial dye concentrations, contact time, $\mathrm{pH}$, adsorbent dosage and agitation rate on the adsorption of BR29 were studied. The uptake was very rapid during the first 30 minutes and slowed down as the contact time increased. The adsorption decreased as the initial dye concentration increased while it increased as the adsorbent dosage increased. The uptake of BR29 was highest at $\mathrm{pH} 8$ and the percentage uptake increased as the agitation rate increased. The adsorption kinetics of BR29 onto BPP fitted well to the pseudo-second order kinetic model. Three different isotherm models, which include Langmuir, Freundlich and Brunauer-Emmett-Teller (BET) were used to analyze the equilibrium adsorption data of BR29. The adsorption isotherm of BR29 onto BPP was better described by the Freundlich isotherm model with the coefficient of determination $\left(R^{2}\right)$ of 0.9956 .
\end{abstract}

Keywords: Basic Red 29, Dye, Adsorption, Banana peel, Kinetic study

\section{INTRODUCTION}

Dyes are colored substances that can be applied to impart color to other materials such as textiles, paper, plastics, foods and leather. Presently, there are more that hundred thousand varieties of dyes and these can be obtained commercially [1]. The textiles and textile products industries are consider as important and growing sectors in Malaysia. According to the

a Department of Chemical Science, Faculty of Science, Universiti Tunku Abdul Rahman, Jalan Universiti, Bandar Barat, 31900 Kampar, Perak, Malaysia

b Centre for Agriculture and Food Research, Universiti Tunku Abdul Rahman, Jalan Universiti, Bandar Barat, 31900 Kampar, Perak, Malaysia

Corresponding authors: ongst@utar.edu.my; ongst_utar@yahoo.com 
statistics, the industry was the eleventh largest export earner in 2017 . The industry had export valued of approximately RM15.3 billion which comprised $1.6 \%$ of the total manufacturing exports of Malaysia [2]. However, the wet processing operation in textile industry which involves dyeing process produces a lot of dye wastewater. It has been estimated that about 280000 tons of textile dyes effluent is being generated annually around the world [3].

Apart from that, batik, which is the famous textile art in Malaysia has also continuously increased and there are more than a thousand batik factories located on the east coast of Malaysia. As most of the batik industries are comparatively small scale and family-based, they do not have proper wastewater treatment system and therefore, the discharge of the colorants used can cause a serious environmental issue. Moreover, the scattered location of the batik industries has increased the difficulties to create a centralized and comprehensive wastewater treatment system [4].

The release of dye wastewater to the surroundings without prior treatment will inflicts great damage to the ecosystem as dyes are potentially hazardous to aquatic animals and plants $[5,6]$. The bioaccumulation of the dyes in aquatic animal will be passed along the food chain and eventually affects all the organisms. Some of the dyes may cause allergic reaction and/or irritation when in contact with skin, inhaled and ingested. As cationic dyes such as Basic Red 29 (BR29), is much more toxic than all-purpose dyes or fiber reactive dyes, therefore this type of dye must be treated with correspondingly greater respect and caution.

A low-cost yet effective method for wastewater treatment is very crucial for both large scale and small scale textile industries. Adsorption approach is extensively applied for the colorant removal from wastewater. This is because the adsorbent can be prepared using low cost materials such as agricultural waste. Although the conventional adsorption method employed activated carbon (AC) as the adsorbent has exhibited a high efficiency performance, AC remains as a relatively expensive adsorbent. Therefore, nonconventional adsorbents have gained a lot of attention for the reduction of hazardous waste from wastewater.

Nonconventional adsorbents can be categorized into five separate groups including fruit waste, plant remains, living and nonliving biomass, agricultural and industrial waste materials, and natural inorganic materials. These items are used as economical bioadsorbent as they tend to be obtained easily and have good adsorption capacity [7].

Banana is considered as a main fruit crops in Malaysia. According to Department of Agriculture Malaysia (2017), the production of banana was around 350000 metric tons in 2017 which was accounted for $26.4 \%$ of the total major fruits production. The high production of banana will create a large amount of banana peel waste. Although banana peel is commonly used as 
animal feed or fertilizer, efforts have been made to utilize banana peel in other applications, for instance, as an inexpensive bioadsorbent for the withdrawal of dyes and other contaminants [8]. Banana peel consists of large amount of cellulose, hemicelluloses, pectin and lignin that contain hydroxyl, carboxylic and various functional groups [9] that are essential important in the adsorption process The species of banana used in this study was Pisang Nangka or jackfruit banana with the scientific name Musa x paradisiaca. They are categorized as plantains which are members of the banana family with high starch content.

\section{RESULTS AND DISCUSSION}

\section{Characterization of adsorbent}

FTIR Analysis. FTIR spectroscopy was used to analyze the functional groups present on the surface of BPP. The FTIR spectra of BPP before and after the adsorption of BR29 were obtained in the range of 4000 to $400 \mathrm{~cm}^{-1}$ as depicted in Figure 1. There are various functional groups that can be found on the surface of BPP as multiple peaks were shown in the spectra. BPP with various functional groups shows that it has a complex nature and it can act as a good adsorbent [10].

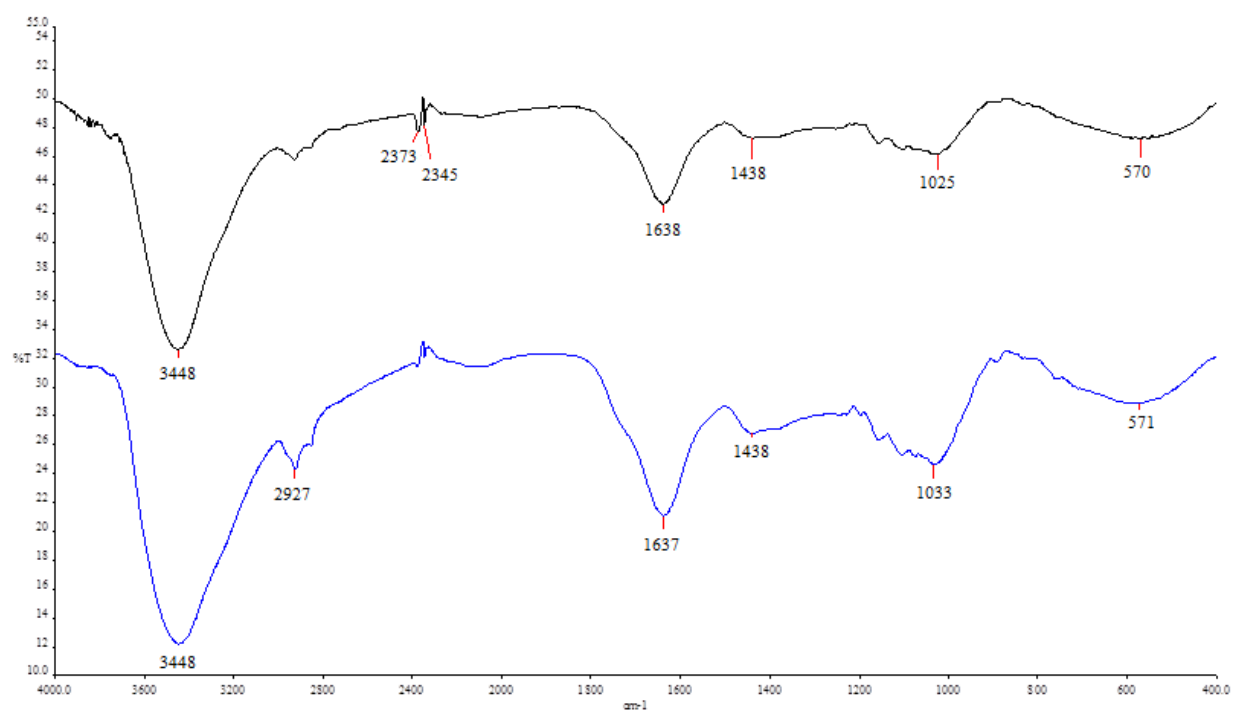

Figure 1. FTIR spectra of BPP before adsorption (black) and after adsorption (blue) of BR29 
The broad and strong adsorption band at $3448 \mathrm{~cm}^{-1}$ was due to the vibration of $\mathrm{O}-\mathrm{H}$ group. This indicates that the hydroxyl group was present on the surface of BPP as the banana peel consists of large amount of cellulose, hemicelluloses, pectin and lignin that contain hydroxyl and carboxylic groups [9]. The peak at $2927 \mathrm{~cm}^{-1}$ represents the stretching vibration of $\mathrm{C}-\mathrm{H}$ group in alkanes. The strong adsorption at $1638 \mathrm{~cm}^{-1}$ represents the stretching of carbon-carbon double bond of aromatic ring that is present in lignin. The peak at $1025 \mathrm{~cm}^{-1}$ indicates the $\mathrm{C}-\mathrm{O}$ stretching vibration and similar findings were reported by Mondal and Kar [11].

The spectrum of BPP after the adsorption of BR29 demonstrated a very close similarity with the one before the adsorption. The peak at 1638 $\mathrm{cm}^{-1}$ was changed to $1637 \mathrm{~cm}^{-1}$ whereas the peak at $1025 \mathrm{~cm}^{-1}$ was shifted to $1033 \mathrm{~cm}^{-1}$. The slight changes observed are most probably because the adhesion of dye molecules onto the BPP is involving adsorption. As this kind of interaction is a surface chemistry process, therefore the spectrum before and after adsorption bear a lots of similarities [12].

Atomic Force Microscope (AFM) Analysis. AFM analysis was performed to inspect the surface topography of the BPP before and after adsorption of the dye. Figures 2(a) and 2(b) represent the AFM micrographs of BPP before and after adsorption, respectively. In Figure 2(a), the surface of BPP without addition of BR29 was observed to be rough and uneven. On the contrary, the micrograph in Figure 2(b) showed that the surface of BPP was relatively more even and smoother after adsorption of BR29. This suggests that the surface of BPP was covered by the dye molecules.

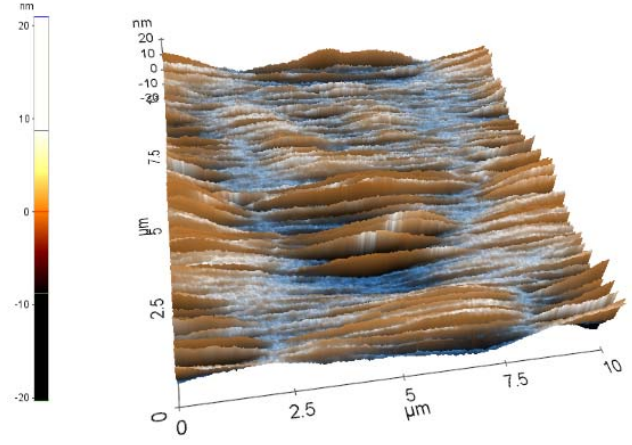

(a)

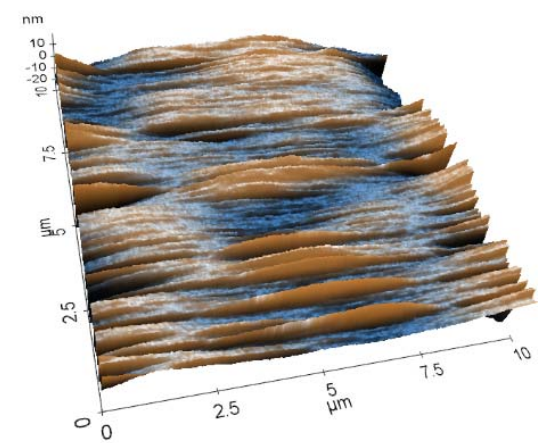

(b)

Figure 2. AFM image of BPP (a) before adsorption (b) after adsorption 
Scanning Electron Microscope (SEM) Analysis. The surface morphology of the BPP before and after adsorption was observed using SEM. This analysis can help to determine the size, the shape and the texture of the sample. The SEM micrographs of BPP before and after adsorption of BR29 with the magnification of 50000x were presented in Figures 3(a) and $3(b)$, respectively. By comparison, the micrograph of BPP before adsorption showed a porous, rough and uneven surface. Conversely, the surface of the BPP becomes smoother and relatively less porous after the adsorption process. This observation agrees well with the previous suggestion whereby after the dye adsorption, the surface will become more even due to the adhesion of dye molecules. Similar result was reported by Pishgar et al. [13] in which the surface morphology of banana peel became smoother after the adsorption of dye as compared to the one before adsorption.

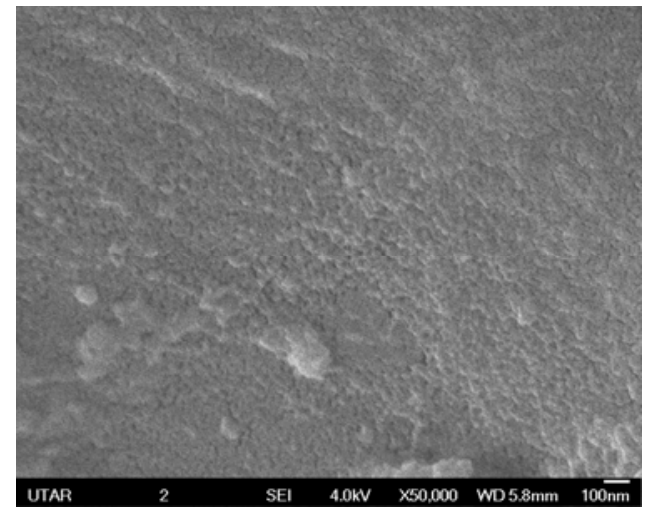

(a)

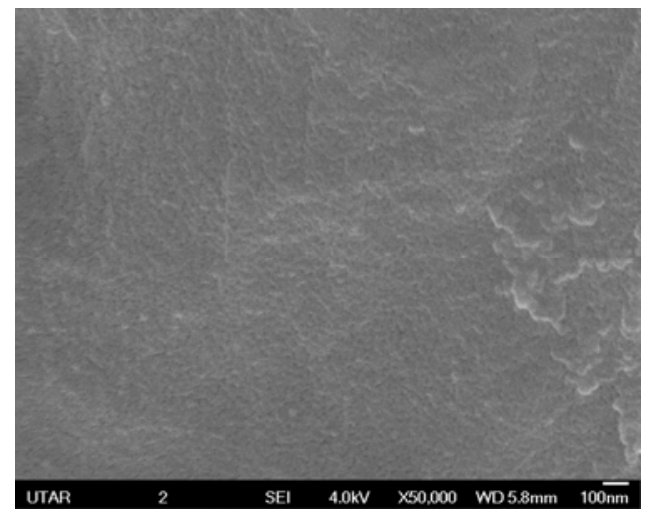

(b)

Figure 3. SEM micrograph of BPP (a) before adsorption (b) after adsorption

\section{Adsorption Studies}

Effect of initial dye concentration and contact time. The trend of the dye uptake for the effect of initial dye concentrations and contact time was illustrated in Figure 4. Generally, the uptake trends of BR29 at different concentrations followed the same pattern in which the percentage uptake increased as the contact time lengthens. The percentage uptake of BR29 was rapid during the first 30 minutes and then followed by a more gradual process until 120 minutes. Thereafter, the rate of adsorption slowed down as it achieves equilibrium. Similar uptake profile was also reported in some of the previous works in the removal of dyes $[14,15]$.

As large amount of surface sites were available for the adsorption of BR29 at the beginning, therefore, the uptake rate was very rapid. As the time progress, the number of remaining surface sites decreased and the adsorption 
rate decreased [16]. The rapid initial rate of adsorption was related to the dye molecules produced a monolayer on the exterior of the BPP. Then, the leisurely internal mass transport stage caused the lower speed of adsorption [17].

When the BR29 concentration was increased from 100 to $500 \mathrm{mg} / \mathrm{L}$, the maximum uptake decreased from $99.55 \%$ to $97.84 \%$. The uptake decreased at higher concentration because the ratio of surface sites available to the amount of BR29 in the solution decreased. As a result, some of the dye molecules were not able to interact with the BPP and the uptake decreased. This also indicated that the dynamic equilibrium of the adsorption was affected by the initial concentration [18]. Similar observation was reported in the adsorption of Maxilon Blue GRL using white marble [19].

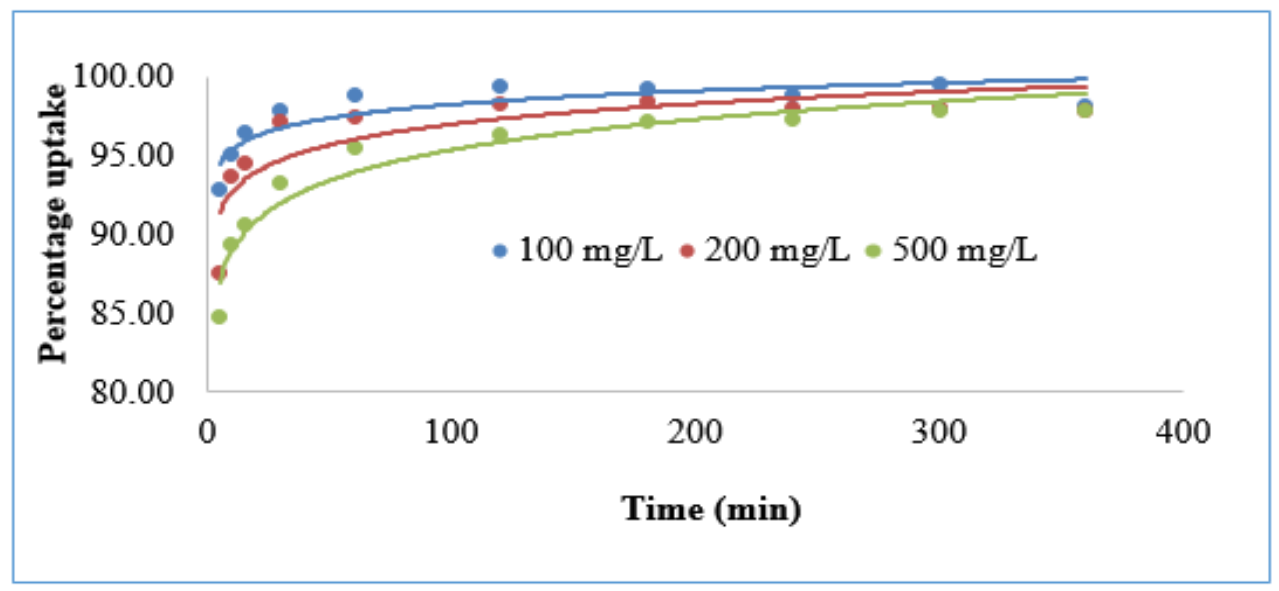

Figure 4. Effect of initial dye concentrations and contact time on percentage uptake of BR29

Effect of $\mathrm{pH}$. The $\mathrm{pH}$ of the dye solution has a large impact on the adsorption process as the surface characteristic of the adsorbent will be changed according to the $\mathrm{pH}$ of the solution. The characteristic of dye molecules will also be altered by the solution's $\mathrm{pH}$ through ionization or dissociation process [10]. The influence of $\mathrm{pH}$ of solution was studied in the $\mathrm{pH}$ range from 2 to 10. The results showed that the uptake of BR29 increased with increasing $\mathrm{pH}$ until the maximum uptake was achieved at $\mathrm{pH} 8$ and then decreased. The maximum uptake was $96.21 \%$ which occurred at $\mathrm{pH} 8$ whereas the uptake was only $87.69 \%$ at $\mathrm{pH} 2$ which was the lowest uptake compared to other $\mathrm{pH}$ values. In acidic condition, the surface active sites of BPP will be protonated as they accept $\mathrm{H}^{+}$ions from the aqueous dye solution. Thus, the surface will be positively charged. Conversely, the BPP will be negatively charged as the functional groups like hydroxyl and carboxylic groups are deprotonated under alkaline condition. 
The $\mathrm{pH}_{\mathrm{pzc}}$ of BPP was determined to be 5.45. Theoretically, the adsorption BR29 as a cationic species onto the BPP will be favored if the $\mathrm{pH}$ of the dye solution was higher than the $\mathrm{pH}_{\mathrm{pzc}}$ of the BPP as the surface carried a net negative charge. Under the alkaline condition and at the $\mathrm{pH}$ greater than $\mathrm{pH}_{\mathrm{pzc}}$ value, the negatively charged BPP will be having electrostatic attraction with the cationic dye molecules and this explained the favorable uptake. However, the uptake decreased from $96.21 \%$ at $\mathrm{pH} 8$ to $95.31 \%$ at $\mathrm{pH} 10$ and this can be related to the dissociation of the dye molecules. According to Washabaugh et. al. [20], the thiazolium ring that is present in the structure of BR29 molecule can undergoes ring opening under the alkaline condition via hydrolysis reaction.

Effect of adsorbent dosage. The results for the influence of adsorbent dosage ranging from 0.01 to $0.10 \mathrm{~g}$ were illustrated in Figure 5. Initially, the percentage uptake increased as the adsorbent dosage increased. The maximum uptake was achieved maximum when the adsorbent dosage was $0.06 \mathrm{~g}$. The further increase in the adsorbent dosage caused a slight decrease in the uptake of the dye. When the mass of BPP used was greater, the number of surface area accessible for the BR29 increased. The highest uptake achieved was $96.94 \%$ with the adsorbent dosage of $0.06 \mathrm{~g}$. The saturation occurred at $0.06 \mathrm{~g}$ at which further increase in adsorbent dosage had caused a slight decrease in the uptake. A lower percentage uptake when the dosage was probably caused by the aggregation of the BPP and thus reducing the sites available for the adsorption of the BR29 species when the adsorbent dosage increased [11].

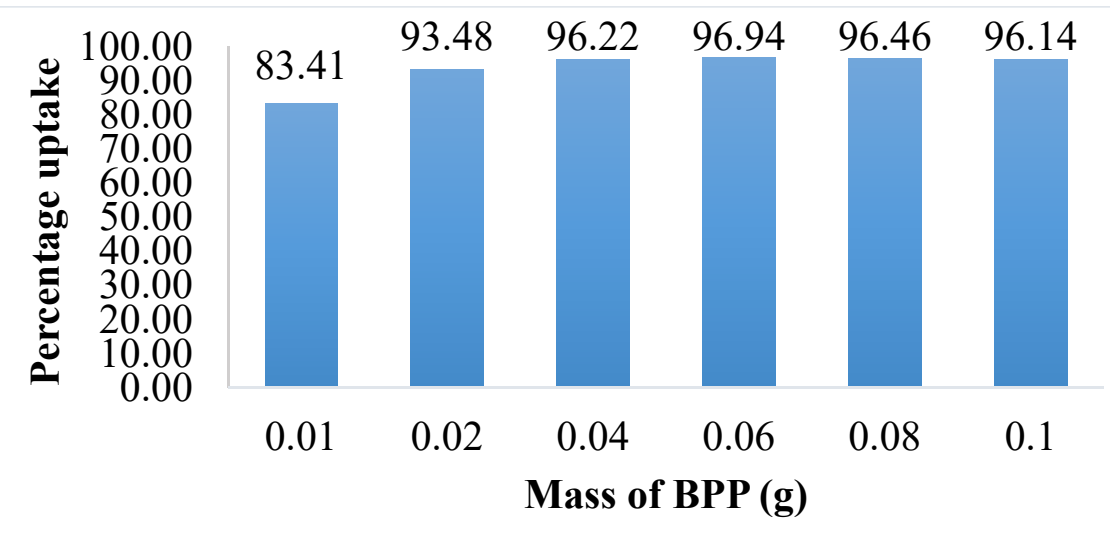

Figure 5. Effect of adsorbent dosage on percentage uptake of BR29 
Effect of agitation rate. The influence of agitation rates was studied using 50 and $100 \mathrm{rpm}$ agitation speed for a period of 240 minutes. The uptake of BR29 occurred very rapidly during the first 60 minutes and then slowed down in for both agitation rates. It was noted that a higher agitation rate resulted in higher percentage uptake of BR29. This is because an increase in the agitation rate will decrease the film resistance to mass transfer surrounding the adsorbent particles thus increase the adsorption of dye molecules. Similarly, Al-Tufaily and Al-Qadi [21] also reported that a higher uptake with increasing agitation speed is due to the increase in turbulence and caused the thickness of boundary layer around the BPP to decrease.

Adsorption kinetics. The kinetic studies can provide insight on the mechanism of the adsorption in a given systems. It also gives information about its possible rate determining stage like chemical interactions or mass transfer process [22]. The pseudo-first order and pseudo-second order kinetic models were applied in this analysis. For pseudo-first order kinetic model, it was developed by Lagergren [23] and thereafter, it has been commonly applied for the adsorption in liquid-solid systems. This linearized equation for this model can be expressed by the formula below:

$$
\log \left(\mathrm{q}_{\mathrm{e}}-\mathrm{q}_{\mathrm{t}}\right)=\log \mathrm{q}_{\mathrm{e}}-\frac{\mathrm{k}_{1}}{2.303} \mathrm{t}
$$

where:

$$
\begin{array}{ll}
\mathrm{q}_{\mathrm{e}} & =\text { amount of BR29 adsorbed at equilibrium }(\mathrm{mg} / \mathrm{g}) \\
\mathrm{q}_{\mathrm{t}} & =\text { amount of BR29 adsorbed at time } \mathrm{t}(\mathrm{mg} / \mathrm{g}) \\
\mathrm{k}_{1} & =\text { rate constant of pseudo-first order kinetics }(1 / \mathrm{min}) \\
\mathrm{t} & =\text { time }(\mathrm{min})
\end{array}
$$

This model considers that the speed of adsorption is relative to the amount of vacant spots available [24]. The $R^{2}$ values for the initial BR29 concentrations of 100,200 and $500 \mathrm{mg} / \mathrm{L}$ were $1.0000,0.8683$ and 0.9370 , correspondingly while the $k_{1}$ values were $0.1175,0.0569$ and 0.0136 with unit of $1 / \mathrm{min}$ in that order. The value of $k_{1}$ represents the rate for the system to achieve equilibrium condition. It decreases when the initial concentration increases because the duration required to achieve equilibrium will increase at higher initial BR29 concentration [25].

On the other hand, the values of calculated $\mathrm{q}_{\mathrm{e}}$ were $1.9297,3.1747$ and $8.4723 \mathrm{mg} / \mathrm{g}$ for 100,200 and $500 \mathrm{mg} / \mathrm{L}$ of BR29 solution, respectively. The calculated $\mathrm{q}_{\mathrm{e}}$ values were considerably different from the $\mathrm{q}_{\mathrm{e}}$ obtained experimentally (Table 1). This proves that the adsorption of BR29 onto BPP 
does not fit well to the pseudo-first order kinetic model. According to Ho and Mckay [26], the Lagergren model typically only relevant during first 20-30 min of the adsorption progression but it is generally not applicable for the whole adsorption process.

Therefore, the pseudo-second order kinetic model was also applied to study the adsorption kinetics of BR29 onto BPP. In this model, the rate determining stage of an adsorption activity was assumed to be the chemical adsorption process. The valence forces in chemisorptions process involves the electrons sharing or exchange between the BR29 and BPP [27]. The linear form equation based on this model is shown below:

In which

$$
\frac{\mathrm{t}}{\mathrm{q}_{\mathrm{t}}}=\frac{1}{\mathrm{k}_{2} \mathrm{q}_{\mathrm{e}}{ }^{2}}+\frac{1}{\mathrm{q}_{\mathrm{e}}} \mathrm{t}
$$

$\mathrm{q}_{\mathrm{t}} \quad=$ amount of BR29 adsorbed at time $\mathrm{t}(\mathrm{mg} / \mathrm{g})$

$\mathrm{q}_{\mathrm{e}} \quad=$ amount of BR29 adsorbed at equilibrium $(\mathrm{mg} / \mathrm{g})$

$\mathrm{k}_{2}=$ rate constant of pseudo-second order kinetics $(\mathrm{g} / \mathrm{mg} \cdot \mathrm{min})$

$\mathrm{t} \quad=$ time $(\mathrm{min})$

The initial adsorption rate, $\mathrm{h}$ can be determined using the formula:

$$
\mathrm{h}=\mathrm{k}_{2} \mathrm{q}_{\mathrm{e}}{ }^{2}
$$

Table 1. Summary of values obtained for pseudo-first and

\begin{tabular}{|c|c|c|c|c|c|c|c|c|c|}
\hline \multirow{2}{*}{$\begin{array}{c}\text { Initial BR29 } \\
\text { concentratio } \\
\text { n (mg/L) }\end{array}$} & \multicolumn{4}{|c|}{ Pseudo-first order } & \multicolumn{5}{|c|}{ Pseudo-second order } \\
\hline & $\begin{array}{c}q_{\text {e cal }} \\
(\mathrm{mg} / \mathrm{g})\end{array}$ & $\begin{array}{c}q_{\text {exp }} \\
(\mathrm{mg} / \mathrm{g})\end{array}$ & $\begin{array}{c}k_{1} \\
(1 / \min )\end{array}$ & $\mathbf{R}^{2}$ & $\begin{array}{c}q_{\text {e cal }} \\
(\mathrm{mg} / \mathrm{g})\end{array}$ & $\begin{array}{c}q_{\text {exp }} \\
(\mathrm{mg} / \mathrm{g})\end{array}$ & $\begin{array}{c}k_{2} \\
(g / m g \cdot \min )\end{array}$ & $\begin{array}{c}\mathrm{h} \\
(\mathrm{mg} / \mathrm{g} \cdot \mathrm{min})\end{array}$ & $\mathbf{R}^{2}$ \\
\hline 100 & 1.9297 & 19.6380 & 0.1175 & 1.0000 & 19.7628 & 19.6380 & 2.3276 & 909.0909 & 0.9999 \\
\hline 200 & 3.1747 & 39.1380 & 0.0569 & 0.8683 & 39.2157 & 39.1380 & 0.0856 & 131.5789 & 1.0000 \\
\hline 500 & 8.4723 & 97.8405 & 0.0136 & 0.9370 & 98.0392 & 97.8405 & 0.0074 & 70.9220 & 1.0000 \\
\hline
\end{tabular}
pseudo-second order kinetics model

The theoretical values of $q_{e}$ calculated were 19.7628, 39.2157 and $98.0392 \mathrm{mg} / \mathrm{g}$ for 100,200 and $500 \mathrm{mg} / \mathrm{L}$ of BR29, correspondingly. The values were comparable to the $\mathrm{q}_{\mathrm{e}}$ values attained experimentally. The $\mathrm{R}^{2}$ values for the three different initial dye concentrations achieved unity or approaching 1. These showed that the adsorption kinetics of BR29 onto BPP followed closely to the pseudo-second order kinetic model. The $\mathrm{k}_{2}$ values were $2.3276,0.0856$ and $0.0074 \mathrm{~g} / \mathrm{mg} \cdot \min$ for 100,200 and $500 \mathrm{mg} / \mathrm{L}$ of 
BR29 solution, respectively. The higher $k_{2}$ value means that the adsorption process will achieve equilibrium in shorter time. The parameters obtained for each of the kinetic model were summarized in Table 1.

In order to obtain the generalized predictive model for BR29 at any contact time and initial concentration, the corresponding linear plots of the pseudo-second order equation were regressed to obtain the constants related to the respective equations [28]. The theoretical model for the amount of BR2 9 adsorbed at any initial concentration, $C_{o}$ and time was expressed by the formula:

$$
\mathrm{q}_{\mathrm{t}}=\frac{\mathrm{C}_{\mathrm{o}} \mathrm{t}}{0.0166 \mathrm{C}_{\mathrm{o}}-1.5918+\left(0.000076 \mathrm{C}_{\mathrm{o}}+5.0863\right) \mathrm{t}}
$$

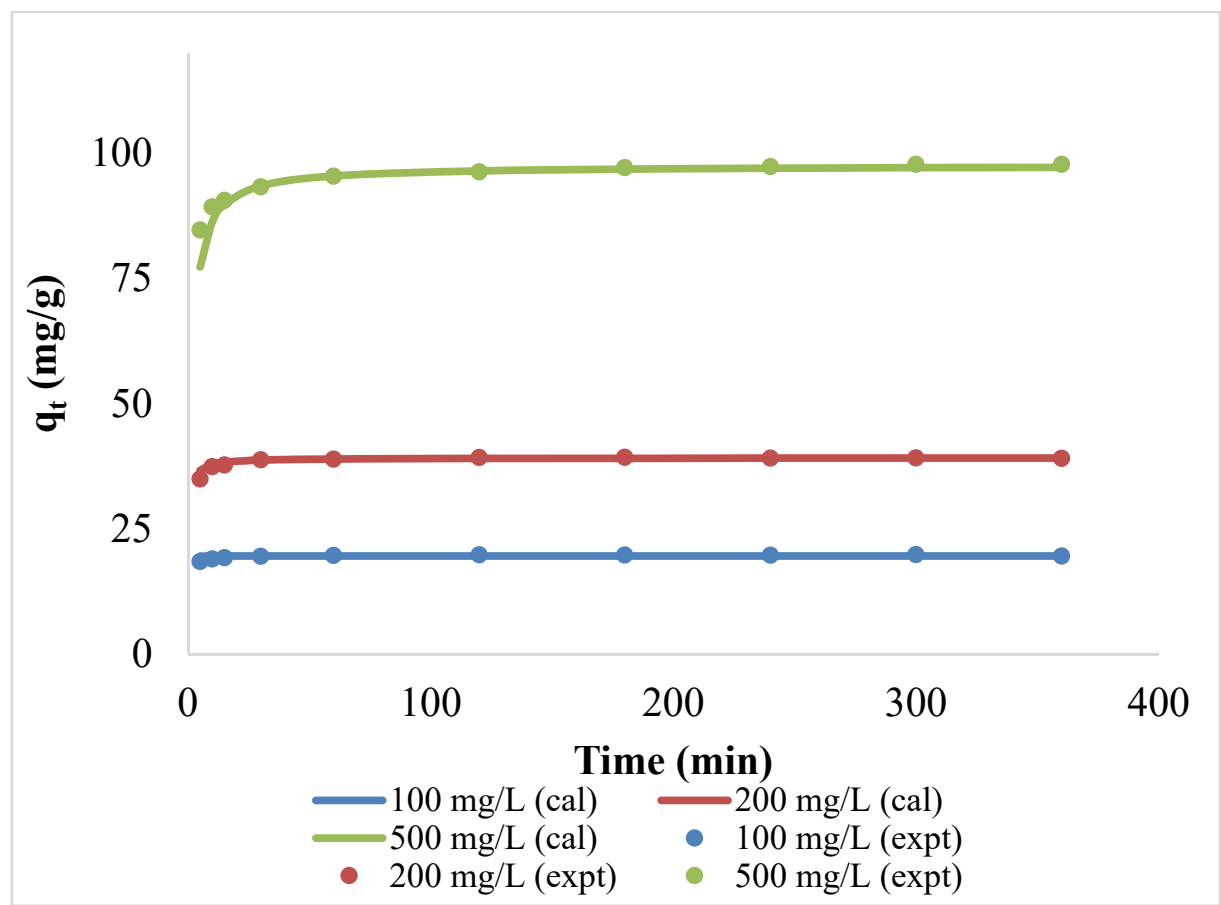

Figure 6. Comparison between the experimental values (expt) and theoretical values (cal) of $q_{t}$

Figure 6 showed the correlation between the data obtained during the analysis and theoretical data of $\mathrm{q}_{t}$ for the adsorption of BR29 by BPP. The experimental data showed an appreciable consistency with the graphs generated for the theoretical values. The graph also showed that the amount 
of BR29 adsorbed was higher when the starting BR29 concentration was higher. The greater initial BR29 concentration offers a greater propulsive strength of concentration gradient to surpass the mass transfer resistances of the BR29 between the BPP and the solution [29].

Adsorption isotherm. The adsorption isotherm involves the equilibrium situation in which the speed of adsorption of BR29 onto the surface of BPP is equal to the speed of desorption of the BR29 from the BPP. Therefore, the concentration of BR29 solution will remain constant at equilibrium [30]. Three different isotherm models including Langmuir [31], Freundlich [32] and Brunauer-Emmet-Teller (BET) [33] models were applied in the study. The Langmuir model assumes monolayer adsorption over a homogenous adsorption sites with no association happens between the adsorbed species. The following linear form of the equation was proposed for this model:

$$
\frac{\mathrm{C}_{\mathrm{e}}}{\mathrm{q}_{\mathrm{e}}}=\frac{\mathrm{C}_{\mathrm{e}}}{\mathrm{q}_{\mathrm{m}}}+\frac{1}{\mathrm{~K}_{\mathrm{L}} \mathrm{q}_{\mathrm{m}}}
$$

In which

$\mathrm{C}_{\mathrm{e}} \quad=$ concentration of BR29 at equilibrium ( $\left.\mathrm{mg} / \mathrm{L}\right)$

$\mathrm{q}_{\mathrm{e}} \quad=$ amount of BR29 adsorbed at equilibrium $(\mathrm{mg} / \mathrm{g})$

$\mathrm{q}_{\mathrm{m}} \quad=$ maximum amount of BR29 adsorbed $(\mathrm{mg} / \mathrm{g})$

$\mathrm{K}_{\mathrm{L}} \quad=$ Langmuir constant $(\mathrm{L} / \mathrm{mg})$

From the graph of $\mathrm{C}_{\mathrm{e}} / \mathrm{q}_{\mathrm{e}}$ against $\mathrm{C}_{\mathrm{e}}$, the values of $\mathrm{q}_{\mathrm{m}}$ and $\mathrm{K}_{\mathrm{L}}$ were $175.4386 \mathrm{mg} / \mathrm{g}$ and $0.1011 \mathrm{~L} / \mathrm{mg}$, respectively and these were obtained from the $y$-intercept and the slope of the graph. The $R^{2}$ for the linear plot was 0.9866 .

The separation factor $\left(R_{L}\right)$ is a dimensionless constant and act as an indispensable feature of Langmuir isotherm. $R_{L}$ can be represented by the formula below:

In which

$$
\mathrm{R}_{L}=\frac{1}{1+\mathrm{K}_{\mathrm{L}} \mathrm{C}_{\mathrm{o}}}
$$

$\mathrm{R}_{\mathrm{L}} \quad$ = separation factor

$\mathrm{K}_{\mathrm{L}} \quad=$ Langmuir constant $(\mathrm{L} / \mathrm{mg})$

$\mathrm{C}_{\mathrm{o}} \quad=$ initial dye concentration $(\mathrm{mg} / \mathrm{L})$

The $R_{L}$ values for all of the BR29 concentration fell in the category $0<R_{L}<1$, and therefore, the adsorption of BR29 onto BPP was favorable. 
The Freundlich isotherm is an exponential equation and can be applied in the situation involving multilayer adsorption, adsorption on heterogeneous surfaces and possibility of reversible adsorption. The linear form of the equation is shown as below:

$$
\log \mathrm{q}_{\mathrm{e}}=\frac{1}{\mathrm{n}} \log \mathrm{C}_{\mathrm{e}}+\log K_{F}
$$

In which

$$
\begin{array}{ll}
\mathrm{q}_{\mathrm{e}} & =\text { amount of BR29 adsorbed at equilibrium }(\mathrm{mg} / \mathrm{g}) \\
\mathrm{n} & =\text { Freundlich constant for adsorption intensity } \\
\mathrm{C}_{\mathrm{e}} & =\text { concentration of BR29 at equilibrium }(\mathrm{mg} / \mathrm{L}) \\
\mathrm{K}_{\mathrm{F}} & =\text { Freundlich constant for adsorption capacity }(\mathrm{mg} / \mathrm{g})(\mathrm{mg} / \mathrm{L})^{\mathrm{n}}
\end{array}
$$

A high $\mathrm{R}^{2}$ value of 0.9956 was obtained for the Freundlich model. The similar findings were reported in the uptake of Basic Blue 9 by using rise husk [34] and the uptake of Basic Violet 10 dye using outer skin of fruit [35] in which the adsorption processes were well described by this model. The number of $1 / \mathrm{n}$ and $\mathrm{K}_{\mathrm{F}}$ obtained were 0.4962 and 26.0615 , correspondingly. The figure of $1 / n$ signifies the strength of the adsorption. If $1 / n$ falls within the range of 0 to 1 , it is related to the chemisorption process and the heterogeneity increases as the value approaches 0 . If the value goes above 1 , it shows that cooperative adsorption occurred [36].

The BET isotherm model is the extended theory for multilayer adsorption from Langmuir equation with the following assumption: (i) all surface adsorption sites are homogeneous; (ii) the heat of adsorption of second and following layers are equal to heat of liquefaction; (iii) no sideways association happens between the adsorbed species.

The formula below was proposed for this model:

$$
q_{e}=\frac{q_{m} K_{B} C_{e}}{\left(C_{s}-C_{e}\right)\left[1+\left(K_{B}-1\right)\left(C_{e} / C_{s}\right)\right]}
$$

Rearrangement of Equation (8) into linear form:

$$
\frac{\mathrm{C}_{\mathrm{e}}}{\left(\mathrm{C}_{\mathrm{s}}-\mathrm{C}_{\mathrm{e}}\right) \mathrm{q}_{\mathrm{e}}}=\frac{\left(\mathrm{K}_{\mathrm{B}}-1\right)}{\mathrm{K}_{\mathrm{B}} \mathrm{q}_{\mathrm{m}}}\left(\frac{C_{e}}{C_{s}}\right)+\frac{1}{K_{B} q_{m}}
$$

In which

$\mathrm{C}_{\mathrm{e}} \quad=$ concentration of BR29 at equilibrium $(\mathrm{mg} / \mathrm{L})$

$\mathrm{C}_{\mathrm{s}} \quad=$ monolayer saturation concentration of BR29 $(\mathrm{mg} / \mathrm{L})$

$\mathrm{q}_{\mathrm{e}} \quad=$ amount of BR29 adsorbed at equilibrium $(\mathrm{mg} / \mathrm{g})$ 
$\mathrm{q}_{\mathrm{m}} \quad=$ maximum amount of BR29 adsorbed $(\mathrm{mg} / \mathrm{g})$

$\mathrm{K}_{\mathrm{B}} \quad=\mathrm{BET}$ adsorption constant

The parameters and $R^{2}$ values obtained for all the isotherm models were summarized in Table 2. Based on the $R^{2}$ value, the adsorption of BR29 is better described by Freundlich model as compared to Langmuir and BET models.

Table 2. Values obtained from Langmuir, Freundlich, and BET isotherm model

\begin{tabular}{|c|c|c|c|c|c|c|c|c|}
\hline \multicolumn{3}{|c|}{ Langmuir } & \multicolumn{3}{c|}{ Freundlich } & \multicolumn{3}{c|}{ BET } \\
\hline $\begin{array}{c}\mathrm{q}_{\max } \\
(\mathrm{mg} / \mathrm{g})\end{array}$ & $\begin{array}{c}\mathrm{K}_{\mathrm{L}} \\
(\mathrm{L} / \mathrm{mg})\end{array}$ & $\mathrm{R}^{2}$ & $\mathrm{~K}_{\mathrm{f}}$ & $\mathrm{n}$ & $\mathrm{R}^{2}$ & $\mathrm{~K}_{\mathrm{B}}$ & $\mathrm{q}_{\max }(\mathrm{mg} / \mathrm{g})$ & $\mathrm{R}^{2}$ \\
\hline 175.439 & 0.101 & 0.987 & 26.062 & 0.496 & 0.996 & 175.052 & 28.563 & 0.987 \\
\hline
\end{tabular}

\section{CONCLUSIONS}

Banana peel powder (BPP) was selected as an economical adsorbent for the adsorption of BR29 from aqueous solution. From the FTIR spectrum, a slight shifting of the peaks was observed. Both AFM and SEM micrographs showed that the surface of the BPP was relatively smoother and more even after the adsorption of BR29. Based on the results obtained from the initial dye concentrations and contact time, the percentage uptake increased significantly during the first 30 minutes and slowed down after that. The uptake improved at higher adsorbent quantity and it achieve maximum when the mass of adsorbent was $0.06 \mathrm{~g}$. The adsorption of BR29 was favored under alkaline condition and the efficiency of uptake amplified as the agitation rate increased.

The adsorption kinetics of BR29 onto BPP was associated with the pseudo-second order kinetic model. The adsorption isotherm of BR29 onto BPP can be better described by the Freundlich isotherm model with a higher $R^{2}$ value. Based on Langmuir isotherm, the maximum amount of BR29 adsorbed onto BPP was $175.4386 \mathrm{mg} / \mathrm{g}$.

\section{EXPERIMENTAL SECTION}

\section{Preparation of adsorbent}

Banana peels were obtained from a banana fritters stall in Kampar, Perak. The banana peels collected were cut into smaller sizes. Then, tap water was used to clean the banana peels followed by washing with distilled water to remove any dirt or impurities. The peels were dried using an oven at 
$60^{\circ} \mathrm{C}$ for period of one day. The dried banana peels were ground into powder form. The banana peel powder (BPP) was soaked in distilled water at $60^{\circ} \mathrm{C}$ with occasional stirring for decolorizing purpose. Furthermore, the BPP was filtered through filter bag and then rinsed with distilled water. The decolorizing process was repeated for another 5 times. After that, the powder was dried again for 24 hours. The BPP obtained was sieved through a sieve with the size of $1 \mathrm{~mm}$. Finally, the dried BPP was stored in plastic bag with seal for further experiment.

\section{Preparation of Basic Red 29 (BR29)}

BR29 was selected as an adsorbate in the studies. BR29 or also known as Basacryl Red GL with the formula of $\mathrm{C}_{19} \mathrm{H}_{17} \mathrm{CIN}_{4} \mathrm{~S}$ is having a molecular mass of $368.88 \mathrm{~g} / \mathrm{mol}$. The BR29 was acquired from Sigma-Aldrich Co. and employed directly without alteration. 1 gram of BR29 was weighed accurately and dissolved in 1 liter of distilled water to prepare a stock solution of $1000 \mathrm{mg} / \mathrm{L}$. The stock solution was covered with aluminum foil and kept in the cabinet to prevent exposure to light. This is because the dye solution might degrade when exposed to light. The stock solution was diluted to different concentrations needed throughout the experiment.

\section{Characterisation of adsorbent}

\section{Fourier Transform Infrared (FTIR) Spectroscopy}

The BPP before adsorption and after adsorption were analyzed using Perkin Elmer FTIR Spectrum RX1 to identify the functional groups associated with the adsorbent. The spectra were obtained in the infrared region with the wavenumber range from 4000 to $400 \mathrm{~cm}^{-1}$. The $\mathrm{KBr}$ pellet method was used in the analysis. The BPP was finely ground with $\mathrm{KBr}$ salt. The mixture was compacted under high pressure to form the $\mathrm{KBr}$ pellet. Finally, the pellet was analyzed using the FTIR spectrometer.

Atomic Force Microscope (AFM)

The surface topography of the BPP was examined using AFM with the model of Park Systems EX-7 with a scan area of $10 \mu \mathrm{m} \times 10 \mu \mathrm{m}$.

Scanning Electron Microscope (SEM)

Field emission scanning electron microscope was used to study the surface morphology of the BPP before and after adsorption. The model used was JEOL JSM 6701F FESEM with emission current of $4 \mathrm{kV}$ and working distance of $5.8 \mathrm{~mm}$. 
Point of zero charge $\left(\mathrm{pH}_{\mathrm{pzc}}\right)$ of adsorbent

The $\mathrm{pH}$ at point of zero charge $\left(\mathrm{pH}_{\mathrm{pzc}}\right)$ was analyzed for the BPP. The sodium chloride $(\mathrm{NaCl})$ solutions with the $\mathrm{pH}$ of 2, 4, 6, 8, 10 and 12 were prepared. $0.01 / 0.1 \mathrm{M}$ of $\mathrm{HCl}$ and $0.01 / 0.1 \mathrm{M} \mathrm{NaOH}$ were used to adjust the $\mathrm{pH}$ of the solution to the selected $\mathrm{pH}$. Then, $0.10 \mathrm{~g}$ of BPP was added to $50 \mathrm{~mL}$ of $0.1 \mathrm{M}$ sodium chloride solution at each $\mathrm{pH}$. The mixture was shaken for 24 hours. The final $\mathrm{pH}$ of each solution was examined after 24 hours. The change in the $\mathrm{pH}(\Delta \mathrm{pH})$ of each solution was calculated. A graph of $\Delta \mathrm{pH}$ versus initial $\mathrm{pH}$ was plotted and the $\mathrm{pH}_{\mathrm{pzc}}$ was obtained as the $\mathrm{x}$-intercept of the plot.

\section{Batch experiments}

The batch study was performed in duplicates and the presented result was the average value obtained from the experiment. The concentration of BR29 solution was measured using Shimadzu UV-Vis Double Beam Spectrophotometer at the maximum wavelength of $510 \mathrm{~nm}$. Dilution of sample was carried out if the absorbance value exceeds the highest point in the standard calibration graph. The percentage uptake of BR29 solution was evaluated using the equation:

$$
\text { Percentage uptake }=\frac{\mathrm{C}_{\mathrm{o}}-\mathrm{C}_{\mathrm{t}}}{\mathrm{C}_{\mathrm{o}}} \times 100 \%
$$

In which

$\mathrm{C}_{\circ}=$ Initial concentration of BR29 $(\mathrm{mg} / \mathrm{L})$

$\mathrm{C}_{\mathrm{t}} \quad=$ Concentration of BR29 at time $\mathrm{t}(\mathrm{mg} / \mathrm{L})$

The BR29 solutions with the concentration of 100,200 and $500 \mathrm{mg} / \mathrm{L}$ were used to analyze the effect of initial concentration on the uptake of the dye. A $20 \mathrm{~mL}$ of BR29 solution at the respective concentration was placed in centrifuge tubes. Then, $0.10 \mathrm{~g}$ of BPP was added to the BR29 solutions. The mixture was agitated at $150 \mathrm{rpm}$ for $5,10,15,30,60,90,120,180,240,300$ and 360 minutes.

The $\mathrm{pH}$ of the BR29 solution was regulated with drop wise addition of $0.01 / 0.1 \mathrm{M}$ hydrochloric acid $(\mathrm{HCl})$ and $0.01 / 0.1 \mathrm{M}$ sodium hydroxide $(\mathrm{NaOH})$. A series of solutions with the $\mathrm{pH} \mathrm{2,} \mathrm{4,} \mathrm{6,} 8$ and 10 were prepared. The parameter was conducted using $100 \mathrm{mg} / \mathrm{L}$ of BR29 at the corresponding $\mathrm{pH}$.

Different adsorbent dosage of $0.01,0.02,0.04,0.06,0.08$ and $0.10 \mathrm{~g}$ of BPP were used for this study. Each different mass of adsorbent was added to $100 \mathrm{mg} / \mathrm{L}$ of BR29 during the analysis. 
A $100 \mathrm{mg} / \mathrm{L}$ of BR29 solution with BPP was agitated at $50 \mathrm{rpm}$ at the time interval of $5,10,15,30,60,90,120,180$ and 240 minutes. This step was repeated by using $100 \mathrm{rpm}$ agitation rate.

Different concentrations of BR29 solution were used in the isotherm study. The BR29 solutions with the concentration of $200,300,400,500,600$ and $700 \mathrm{mg} / \mathrm{L}$ were prepared. A $0.10 \mathrm{~g}$ of BPP was added to $20 \mathrm{~mL}$ of BR29 solution at each concentration and shaken at 150 rpm for 240 minutes.

\section{ACKNOWLEDGEMENTS}

The financial support and research facilities by Universiti Tunku Abdul Rahman are acknowledged.

\section{REFERENCES}

1. S.L. Lee, S.W. Liew, S.T. Ong; Acta Chim. Slov., 2016, 63, 144-153.

2. Malaysian Investment Development Authority, Textiles and Textile Products [Online], 2019 Available at: http://www.mida.gov.my/home/textiles-and-textileproducts/posts/

3. Y.L. Pang, A.Z. Abdullah; CLEAN - Soil, Air, Water, 2013, 41, 751-764.

4. P.M. Birgani, N. Ranjbar, R.C. Abdullah, K.T. Wong, G. Lee, S. Ibrahim, C. Park, Y. Yoon, M. Jang; J. Environ. Manage., 2016, 184, 229-239.

5. D.A. Yaseen, M. Scholz; Environ. Sci. Pollut. Res. Int., 2018, 25, 1980-1997.

6. S. Syafalni, I. Abustan, I. Dahlan, K.W. Chan, G. Umar; Mod. Appl. Sci., 2012, 6, 37-51.

7. P.D. Pathak, S.A. Mandavgane, B.D. Kulkarni; Rev. Chem. Eng., 2015, 31, 361-381.

8. G. Annadurai, R.S. Juang, D.J. Lee; J. Hazard. Mater., 2002, 92, 263-274.

9. P.D. Pathak, S.A. Mandavgane, B.D. Kulkarni; Curr. Sci., 2017, 113, 444-454.

10. M. Dahiru, Z.U. Zango, M.A. Haruna; Am. J. Mater. Sci., 2018, 8, 32-38.

11. N.K. Mondal, S. Kar; Appl. Water Sci., 2018, 8, 157-169.

12. H. Y. Gan, L. E. Leow, S. T. Ong; Acta Chim. Slov., 2017, 64, 144-158.

13. M. Pishgar, M.E. Yazdanshenas, M.H. Ghorbani, K. Farizadeh; J. Appl. Chem. Res., 2013, 7, 51-62.

14. S.W. Liew, S.T. Ong; Asian J. Chem., 2014, 26, 3808-3814.

15. H.J. Lee, S.T. Ong; Environ. Prot. Eng. J., 2017,43, 169-181.

16. M.N. Idris, Z.A. Ahmad, M.A. Ahmad; Int. J. Basic Appl. Sci., 2011, 11, 38-43.

17. A. Salama, H.A. Aljohani, K.R. Shoueir; Mater. Lett., 2018, 230, 293-296.

18. Ü. Geçgel, G. Özcan, G.Ç. Gürpınar; J. Chem., 2013, Article ID 614083,1.

19. A.M.K. Aljebori, A.N. Alshirifi; Asian J. Chem., 2012, 24, 5813-5816.

20. M.W. Washabaugh, M.A. Gold, C.C. Yang; J. Am. Chem. Soc., 1995, 117, 7657-7664.

21. M.A.M. Al-Tufaily, Z.S.R. Al-Qadi; Int. J. Civ. Eng. Technol., 2016, 7, 1-14. 
22. S.K. Kim, J. Venkatesan, Introduction to Marine Biotechnology, in Handbook of Marine Biotechnology, S.K. Kim Ed.; Springer-Verlag, Berlin Heidelberg, Swizerland, 2015, Chapter 1, pp. 1-10.

23. S. Lagergren; Handlingar, 1898, 24, 1-39.

24. M. Ghasemi, N. Ghasemi, G. Zahedi, S.R.W. Alwi, M. Goodarzi, H. Javadian; Int. J. Environ. Sci. Technol., 2014, 11, 1835-1844.

25. F.E. Soetaredjo, S. Ismadji, K. Foe, G. L. Woworuntu, Removal of Hazardous Contaminants from Water or Wastewater Using Polymer Nanocomposites Materials, in Nanotechnology for sustainable water resources, A.K. Mishra, C.M. Hussain Eds.; Scrivener Publishing, New Jersey, USA, 2018, Chapter 4, pp. 103-139.

26. Ho, and McKay, G.; Trans. Inst. Chem. Eng., 1998, 76, 332-340.

27. Y.S. Ho, G. McKay; Pr. Biochem., 1999, 34, 451-465.

28. Y. S. Ho, G. McKay; Water Res., 2000, 34, 735-742.

29. G.L. Dotto, S.K. Sharma, L.A.A. Pinto, Biosorption of Organic dyes: Research Opportunities and Challenges, in Green chemistry for dyes removal from wastewater, S.K. Sharma Ed.; Scrivener Publishing, New Jersey, USA, 2018, Chapter 8, pp. 295-323.

30. Y.T. Huang, M.C. Shih, Int. J. Sci. Res. Pub., 2016, 6, 548-554.

31. I. Langmuir; J. Am. Chem. Soc., 1916, 38, 2221-2295.

32. H. M. F. Freundlich; J. Phys. Chem., 1906, 57, 385-471.

33. S. Brunauer, P. H. Emmett, E. Teller; J. Am. Chem. Soc., 1938, 60, 309-319.

34. A.N. Labaran, Z.U. Zango, U. Armaya'u, Z.N. Garba; Sci. World J., 2019, 14, 66-70.

35. A.A. Inyinbor, F.A., Adekola, G.A. Olatunji; Water Resour. Ind., 2016,15, 14-27.

36. A. Sa, A.S. Abreu, I. Moura, A.V. Machado, Polymeric materials for metal sorption from hydric resources, in Water Purification, A. M. Grumezescu Ed., Academic Press, London, UK, 2017, Chapter 8, pp. 289-322. 
